\title{
Un test génetico podría ayudar en el diagnóstico de nódulos tiroideos citológicamente indeterminados
}

\author{
A genetic test could help in diagnosis of cytologically indeterminate thyroid nodules
}

Alexander EK, y col. N Engl J Med. 2012;367(8):705-15.

\section{Objetivo}

Validar el clasificador tiroideo de expresión genética en pacientes con nódulos tiroideos con citología indeterminada por punción aspiración con aguja fina (PAAF).

\section{Diseño, lugar y tiempo}

Estudio prospectivo, doble ciego. Realizado en 49 locaciones de Estados Unidos entre Junio 2009 a Diciembre 2010.

\section{Criterios de inclusión}

Pacientes con nódulos tiroideos mayores a $1 \mathrm{~cm}$ por ecografía, con citología indeterminada por PAAF; edad $\geq 21$ años.

\section{Test de referencia}

Histopatología post quirúrgica: dos patólogos analizaron la muestra quirúrgica en forma independiente. En caso de desacuerdo, discutían el caso y, de no llegar a un consenso, un tercero emitía su opinión.

\section{Test en estudio}

Clasificador genético binario: desarrollado utilizando el array de exones humanos, un dispositivo que cuantifica todos los exones transcriptos (ARNm) en una célula, proveyendo un perfil de expresión completo para cada muestra.

\section{Resultados}

Se obtuvieron 4.812 aspirados de 3.789 pacientes; 413 tuvieron citología indeterminada por PAAF y posterior análisis histopatológico; 265 aspirados constituyeron la muestra final
(148 fueron excluidas por: no cumplir criterios de inclusión, muestras insuficientes, problemas en el transporte).

Tabla 1: Características operativas del test en estudio.

\begin{tabular}{|c|c|c|c|c|}
\hline \multirow{2}{*}{ Test en estudio } & \multicolumn{2}{|c|}{$\begin{array}{c}\text { Gold Standard* } \\
\text { (histopatología) } \\
N=265\end{array}$} & \multicolumn{2}{|c|}{$\begin{array}{c}\text { Caracteristicas operativas } \\
\text { (histopatologia) } \\
N=265\end{array}$} \\
\hline & $\begin{array}{c}\text { Maligno } \\
\mathrm{N}=85\end{array}$ & $\begin{array}{c}\text { Benigno } \\
\mathrm{N}=180\end{array}$ & $\begin{array}{l}\text { Sensibilidad } \\
\text { (IC95\%) }\end{array}$ & $\begin{array}{c}\text { Especificidad* } \\
\text { (IC95\%) }\end{array}$ \\
\hline Sospechoso de malignidad & 78 & 87 & 0,92 & 0,52 \\
\hline Benigno & 7 & 93 & $(0,84$ a 0,97$)$ & $(0,44$ a 0,59$)$ \\
\hline
\end{tabular}

Un análisis posterior usando marcadores moleculares determinó que en seis de los siete falsos negativos la muestra de células foliculares era insuficiente para el diagnóstico. Los factores demográficos y clínicos no se asociaron con un resultado falso negativo.

No se encontraron diferencias en cuanto a género, edad, factores de riesgo (radioterapia y antecedentes familiares), y tamaño del nódulo.

\section{Conclusión}

Estos datos sugieren la consideración de un enfoque más conservador para los pacientes con nódulos tiroideos citológicamente indeterminados en la PAAF y benignos según los resultados del clasificador de expresión genética.

Fuente de financiamiento: Veracyte.

\section{Comentario}

Entre el $5 \%$ a $15 \%$ de los nódulos tiroideos $>1 \mathrm{~cm}$ son malignos; por lo cual el tamaño sería una indicación de $\mathrm{PAAF}^{1}$. Sin embargo, entre el $15 \%$ y $30 \%$ de las citologías pre-quirúrgicas de estos nódulos son indeterminadas. Estos pacientes suelen ser derivados a cirugía, pese a que la mayoría serán nódulos benignos; un 2 a 10\% tendrán complicaciones postoperatorias y la mayoría requerirá tratamiento sustitutivo con hormona tiroidea ${ }^{2}$.

Asimismo, un $60 \%$ a $70 \%$ de las neoplasias de tiroides tienen al menos una mutación genética conocida; esto permitió desarrollar un clasificador genético binario de nódulos tiroideos, a los cuales clasifica como "benignos" vs. "sospechosos de malignidad"3.

Este estudio presentó algunas limitaciones, la prevalencia de cáncer (32\%) podría ser distinta a la de la población general afectando los valores predictivos. Además el clasificador no diferenció entre resultados falsos negativos y muestra insuficiente.

Según los resultados de este estudio, el clasificador genético, mostró un valor predictivo negativo de $93 \%$ entre los nódulos que habían obtenido un resultado indeterminado por PAAF.

\section{Conclusiones del comentador}

Este test podría ser útil para evitar cirugías. Sin embargo, factores relacionados con su costo y disponibilidad podrían afectar su accesibilidad.

María Victoria Salgado [ Servicio de Medicina Familiar y Comunitaria del Hospital Italiano de Buenos Aires. maria.salgado@ hospitalitaliano.org.ar ]

Salgado MV. Test génetico podría ayudar en el diagnóstico de nódulos tiroideos citológicamente indeterminados. Evid Act Práct Ambul. Oct-Dic. 2012;15(4):135. Comentado de: Alexander EK, Kennedy GC, Baloch ZW, et al. Preoperative Diagnosis of Benign Thyroid Nodules with Indeterminate Cytology. N Engl J Med. 2012 Aug 23;367(8):705-15. PMID: 22731672.

\section{Referencias}

1. Gharib H, Papini E, Paschke R, et al. American Association of Clinical Endocrinologists, Associazione Medicie Endocrinologi, and European Thyroid Association medical guidelines for clinical practice for the diagnosis and management of thyroid nodules: executive summary of recommendations. J Endocrinol Invest2010;33:Suppl:51-56.

2. Cooper DS, Doherty GM, Haugen BR, et al. Revised American Thyroid Association management guidelines for patients with thyroid nodules and differentiated thyroid cancer. Thyroid2009;19:1167-1214[Erratum, Thyroid 2010;20:674-5.]

3. Chudova D, Wilde JI, Wang ET, et al. Molecular classification of thyroid nodules using high-dimensionality genomic data. J Clin Endocrinol Metab2010;95:296-304 